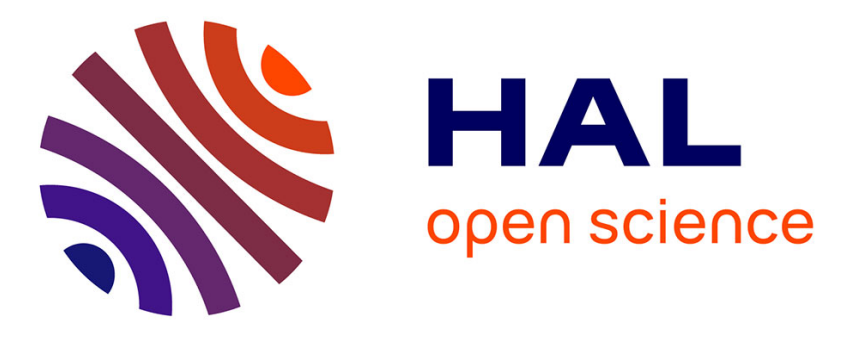

\title{
Modification of Cycling Biomechanics During a Swim-to-Cycle Trial
}

\author{
Anne Delextrat, Véronique Tricot, Thierry Bernard, Fabrice Vercruyssen, \\ Christophe Hausswirth, Jeanick Brisswalter
}

\section{- To cite this version:}

Anne Delextrat, Véronique Tricot, Thierry Bernard, Fabrice Vercruyssen, Christophe Hausswirth, et al.. Modification of Cycling Biomechanics During a Swim-to-Cycle Trial. Journal of Applied Biomechanics, 2005, 21, pp.297 - 308. hal-01762706

\section{HAL Id: hal-01762706 https: / hal-insep.archives-ouvertes.fr/hal-01762706}

Submitted on 10 Apr 2018

HAL is a multi-disciplinary open access archive for the deposit and dissemination of scientific research documents, whether they are published or not. The documents may come from teaching and research institutions in France or abroad, or from public or private research centers.
L'archive ouverte pluridisciplinaire HAL, est destinée au dépôt et à la diffusion de documents scientifiques de niveau recherche, publiés ou non, émanant des établissements d'enseignement et de recherche français ou étrangers, des laboratoires publics ou privés. 


\title{
Modification of Cycling Biomechanics During a Swim-to-Cycle Trial
}

\author{
Anne Delextrat, Véronique Tricot, Thierry Bernard \\ Fabrice Vercruyssen, Christophe Hausswirth ${ }^{2}$ \\ and Jeanick Brisswalter \\ University of Toulon-Var \\ ${ }^{2}$ National Institute of Sport and Physical Education, Paris
}

The aim of this study was to investigate the effects of drafting, i.e., swimming directly behind a competitor, on biomechanical adaptation during subsequent cycling. Eight well-trained male triathletes underwent three submaximal sessions in a counterbalanced order. These sessions comprised a 10-min ride on a bicycle ergometer at $75 \%$ of maximal aerobic power (MAP) at a freely chosen cadence. This exercise was preceded either by a 750-m swim performed alone at competition pace (SCA trial: swimming-cycling alone), a 750-m swim in a drafting position at the same pace as during SCA (SCD trial: swimming-cycling with drafting), or a cycling warm-up at $30 \%$ of MAP for the same duration as the SCA trial (CTRL trial). The results indicated that the decrease in metabolic load when swimming in a drafting position (SCD trial) was associated with a significantly lower pedal rate and significantly higher mean and peak resultant torques when compared to the SCA trial, $p<0.05$. These results could be partly explained by the lower relative intensity during swimming in the SCD trial when compared with the SCA trial, involving a delayed manifestation of fatigue in the muscles of the lower limbs at the onset of cycling.

Key Words: pedal rate, resultant torque, asymmetry, neuromuscular fatigue

Several variations in locomotor pattern have been observed in athletes during middle- and long-distance events. These modifications have mainly been analyzed during unimodal activities and seem to depend on the mode of locomotion. In particular, significant decreases in freely chosen cadence (FCC) from 7 to $18 \mathrm{rev} \cdot \mathrm{min}^{-1}$ have been reported in triathletes during cycling exercises lasting 1 to 2 hours (Lepers, Hausswirth, Maffiuletti, Brisswalter, \& Van Hoecke, 2000; Vercruyssen, Hausswirth, Smith, \& Brisswalter, 2001). Elliot and Roberts (1980)

Sport Ergonomy and Performance Laboratory, University of Toulon-Var, Ave. de l'Université, BP 132, 83957 La Garde cedex, France; ${ }^{2}$ Biomechanics and Physiology Laboratory, National Institute of Sport and Physical Education, 11 Ave. du Tremblay, 75012 Paris, France. 
have shown a significant decrease in stride length (SL) and a significant increase in stride rate (SR) during a 3,000-m run undertaken at constant velocity $\left(5.17 \mathrm{~m} \cdot \mathrm{s}^{-1}\right)$, while Brisswalter, Fougeron, and Legros (1998) did not observe any variation in gait kinematics during a 3-hr walk at competition pace. The recent appearance of multisport activities such as triathlon (swimming-cycling-running) raises new questions relative to the influence of locomotion mode transitions on kinematic adaptation during each discipline.

Triathlon events are characterized by a variety of distances ranging from Sprint (750-m swim, 20-km cycle, 5-km run) to Ironman (3.8-m swim, 180-km cycle, $42.2-\mathrm{km}$ run). From the shortest to the longest distances the relative duration of the swimming, cycling, and running parts represents $18 \%$ to $10 \%, 52 \%$ to $56 \%$, and $30 \%$ to 34\%, respectively (Dengel, Flynn, Costill, \& Kirwan, 1989; Hausswirth, Lehenaff, Dreano, \& Savonen, 1999). Researchers have found significant correlations between cycling and running duration and triathlon performance, whereas no such relationship has been reported with swimming time (Dengel et al., 1989; Schabort, Killian, St Clair Gibson, Hawley, \& Noakes, 2000). Consequently, many studies involved in performance optimization have focused on the adaptation of the locomotor pattern after the cycle-to-run transition (Hausswirth, Bigard, \& Guezennec, 1997; Millet, Millet, \& Candau, 2001; Quigley \& Richards 1996).

One of the most studied parameters in the literature concerns stride characteristics (i.e., SL and SR). The influence of a prior cycling task on these variables during running is not clearly established. Quigley and Richards (1996) found no significant effect of a prior 30-min cycling bout on SL and SR measured during running. In contrast with these results, Hausswirth et al. (1997) observed a significant decrease in SL (7\%) at the start of the running bout of a simulated triathlon (30-min swimming, 60-min cycling, 45-min running) compared with an isolated 45-min run. Moreover, it was reported that decreasing the cycling metabolic load by modifying the geometry of the bicycle frame for a $40-\mathrm{km}$ trial involved significantly higher SL (12\%) and SR (2\%) during the first 5-km of the subsequent running bout. These increases in stride characteristics resulted in a faster mean running speed (Garside \& Doran, 2000).

It is often suggested that these modifications of running kinematics account for the increase in running energy demand classically observed during prolonged exercises. Indeed, significantly higher energy costs have been reported when SL was either increased or decreased from the freely chosen SL (e.g., Cavanagh \& Williams, 1982). The same phenomenon is also observed during cycling, whereby a cadence associated with a minimization of energy demand (energetically optimal cadence) could be identified around $75 \mathrm{rev} \cdot \mathrm{min}^{-1}$ (Vercruyssen et al., 2001). However, to our knowledge the variations in cycling kinematics and energy expenditure have never been examined in the context of a swim-to-cycle trial.

Within this framework, the main purpose of the present study was to investigate the influence of a prior 750-m swim on cycling kinematics. A secondary purpose was to relate these alterations to the metabolic demand of cycling.

\section{Methods}

Eight well trained and motivated male triathletes (age $27 \pm 6$ yrs; height $182 \pm 8$ $\mathrm{cm}$; weight $72 \pm 7 \mathrm{~kg}$; body fat $12 \pm 3 \%$ ) participated in this study. They had been competing in the triathlon at the interregional or national level for at least 3 years. 
Mean $\pm S D$ training distances per week were $5.6 \pm 2.3 \mathrm{~km}$ in swimming, $65 \pm 33$ $\mathrm{km}$ in cycling, and $32 \pm 16 \mathrm{~km}$ in running, which represented $131 \pm 54 \mathrm{~min}, 150$ $\pm 76 \mathrm{~min}$, and $148 \pm 79 \mathrm{~min}$ for these three disciplines, respectively. This training program was mostly composed of technical workouts and interval training in swimming, aerobic capacity (outdoor), and interval training (cycle ergometer) in cycling, and fartlek and interval training in running. It included only one crosstraining session (cycle-to-run) per week. These training volumes and intensities are relatively low when compared to the training load usually experienced by triathletes of this level, partly because the experiment was undertaken in winter when triathletes decrease their training load in all three disciplines. The participants were all familiarized with laboratory testing. They were fully informed of the procedures of the experiment and gave written informed consent prior to testing. The project was approved by the local ethics committee for the protection of individuals (SaintGermain-en-Laye, France).

On their first visit to the laboratory the triathletes underwent two tests. The first test was to determine their leg dominance, in which the 8 participants were classified by kicking dominance according to the method described by Daly and Cavanagh (1976). The second test was a laboratory incremental test on a cycle ergometer to determine maximal oxygen uptake $\left(\mathrm{VO}_{2} \mathrm{max}\right)$ and maximal aerobic power (MAP). After a 6-min warm-up at $150 \mathrm{~W}$, power output was increased by 25 W every 2 minutes until volitional exhaustion. The criteria used for determinating $\mathrm{VO}_{2}$ max were: a plateau in $\mathrm{VO}_{2}$ despite the increase in power output, a heart rate (HR) over $90 \%$ of the predicted maximal heart rate (220 - age in years \pm 10$)$, and a respiratory exchange ratio (RER) over 1.15 (Howley, Bassett, \& Welch, 1995).

On their subsequent visits to the laboratory the triathletes underwent 4 submaximal sessions separated by at least 48 hours (Figure 1). The first session was always a 750-m swim performed alone at a sprint triathlon competition pace (SA trial). It was used to determine the swimming intensity for each participant. The 3 other sessions, presented in counterbalanced order, comprised 2 swim-to-cycle trials and one isolated cycling trial. The cycling test was a 10-min ride on the bicycle ergometer at a power output corresponding to $75 \%$ of MAP and at FCC. During the isolated cycling trial (CTRL trial) this test was preceded by a warm-up on the cycle ergometer at a power output corresponding to 30\% of MAP for the same duration as SA swim. During the swim-to-cycle transitions, the cycling test was preceded either by a 750-m swim performed alone at the pace adopted during SA (SCA trial), or by a 750-m swim at the same pace in a drafting position (i.e., swimming directly behind a competitor in the same lane, SCD trial). The same lead swimmer was used for all participants. He was a highly trained triathlete competing at the international level. In order to reproduce the swimming pace adopted during the SA trial, the triathletes were informed of their performance every $50 \mathrm{~m}$ via visual feedback.

The swim tests took place in the outdoor Olympic swimming pool of Hyères (Var, France); the participants wore a neoprene wet suit (integral wet suit Aqua-

${ }^{\circledR}$, Pulsar 2000; thickness: shoulders $1.5 \mathrm{~mm}$, trunk $4.5 \mathrm{~mm}$, legs $1.5 \mathrm{~mm}$, arms $1.5 \mathrm{~mm}$ ). The cycling tests were conducted near the swimming pool in order to standardize the duration of the swim-to-cycle transition $(3 \mathrm{~min})$. The intensity of 75\% of MAP was chosen because it was close to the pace adopted by triathletes of the same level during sprint triathlon competitions (Hausswirth et al., 1999; Hausswirth, Vallier, Lehenaff, et al., 2001) and close to the intensity used in a 


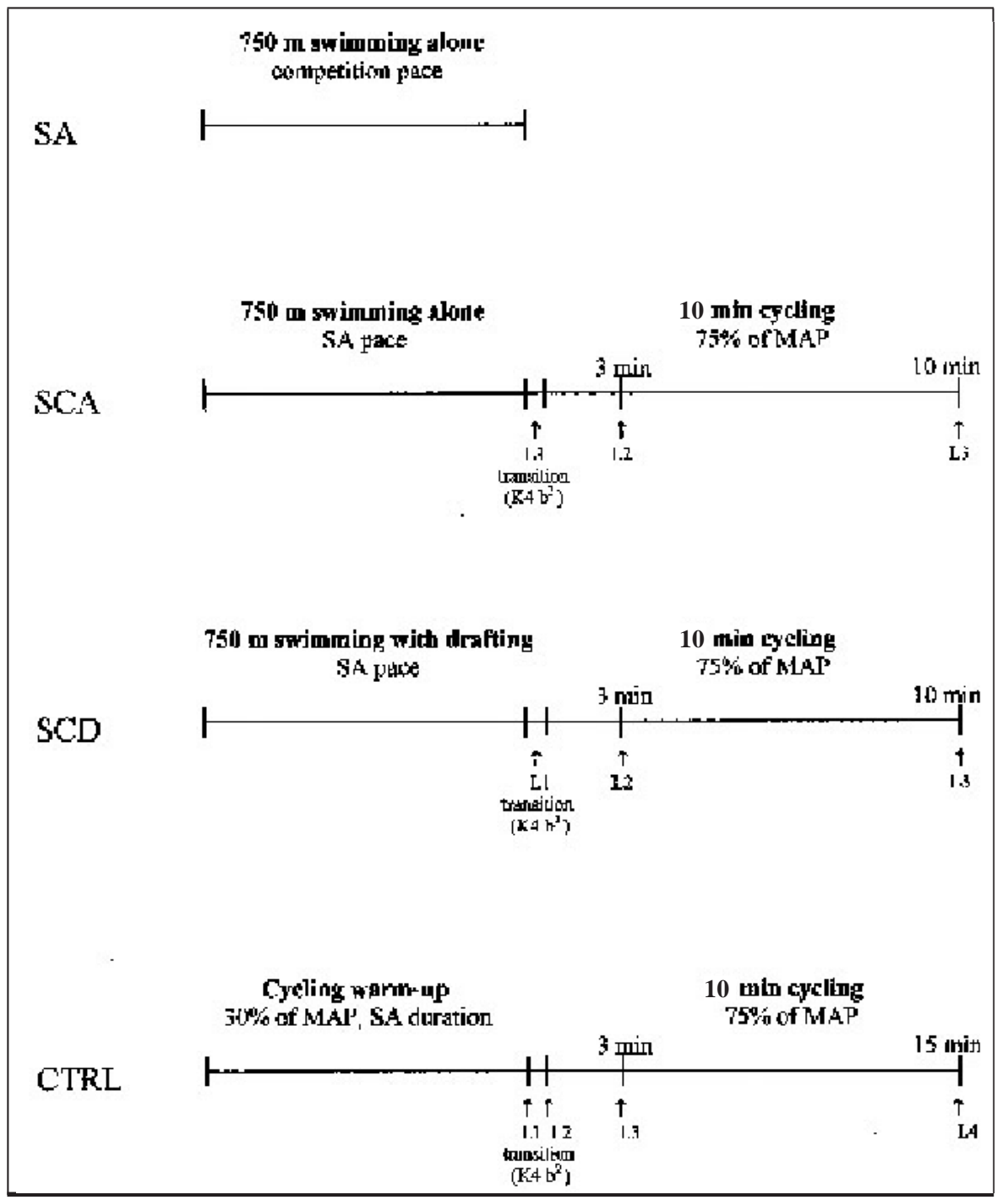

Figure 1 - Experimental protocol. L: blood sampling; $\mathrm{K} 4 \mathrm{~b}^{2}$ : installation of the Cosmed K4 $\mathbf{b}^{2}$ analyzer.

recent study on the cycle-to-run transition in trained triathletes (e.g., Vercruyssen, Brisswalter, Hausswirth, et al., 2002).

All triathletes rode an electromagnetically braked cycle ergometer (SRM Jülich, Welldorf, Germany) equipped with their own pedals and adjusted according to their anthropometrical characteristics. This system can maintain a constant power output independent of the pedal rate spontaneously adopted by the participants. Power output is continuously calculated as shown in Equation 1:

$$
\text { Power }(\mathrm{W})=\text { Torque }(\mathrm{Nm}) \quad \text { Angular Velocity }\left(\mathrm{rad} \cdot \mathrm{s}^{-1}\right)
$$


The torque generated at the crank axle is measured by 20 strain gauges situated between the crank arms and the chain-rings. The deformation of the strain gauges is proportional to the resultant force acting tangentially on the crank (i.e., effective pedaling torque). Pedal rate and torque are inductively transmitted to the power control unit with a sampling frequency of $500 \mathrm{~Hz}$ and data are averaged every 5 seconds and recorded by the power control unit. The SRM system was calibrated prior to each trial. It has been shown to provide a valid and reliable measure of power output when compared with a Monark cycle ergometer (Jones \& Passfield, 1998). From these data, several parameters were calculated for each pedal revolution. An average value of these parameters was then computed during the last $30 \mathrm{~s}$ of each minute

The mean value of the resultant torque exerted during the downstroke of the dominant leg (MTD, in Nm) and during the downstroke of the nondominant leg (MTND, in Nm);

The maximal (peak) value of the resultant torque exerted during the downstroke of the dominant leg (PTD, in Nm) and during the downstroke of the nondominant leg (PTND, in Nm);

The arm crank angle corresponding to PTD (AD, in degrees) and PTND (AND, in degrees). Crank angle was referenced to $0^{\circ}$ at top dead center (TDC) of the right crank arm and to $180^{\circ}$ at the TDC of the left crank arm (thus the right leg downstroke was from $0^{\circ}$ to $180^{\circ}$ and the left leg downstroke was from $180^{\circ}$ to $360^{\circ}$ ). Then the crank angle for the left leg downstroke was expressed relative to the TDC of the left crank arm (i.e., $180^{\circ}$ was subtracted to the value obtained).

In addition to the biomechanical analysis, the participants were asked to report their perceived exertion (RPE) immediately after each trial using the 15-graded Borg scale from 6 to 20 (Borg, 1970). Moreover, physiological effort during swimming and cycling was assessed from heart rate (HR), oxygen uptake $\left(\mathrm{VO}_{2}\right)$, and lactate values. During the cycling trials, $\mathrm{VO}_{2}$ was recorded by the Cosmed $\mathrm{K}^{4} \mathrm{~b}^{2}$ telemetric system (Rome, Italy) recently validated by McLaughlin, King, Howley, Basset, and Ainsworth (2001), and HR was continuously monitored during swimming and cycling using a cardiofrequency meter (Polar vantage, Tampere, Finland). Blood lactate concentration $\left(\mathrm{LA}, \mathrm{mmol} \cdot \mathrm{L}^{-1}\right)$ was measured by the lactate Pro ${ }^{\mathrm{TM}} \mathrm{LT}-1710$ portable lactate analyzer (Arkray, KDK, Kyoto, Japan) from capillary blood samples collected from the participants' earlobes immediately after swimming (L1) and at the 3rd and 10th min of cycling (L2, L3).

From these data, cycling gross efficiency (GE, \%) was calculated as the ratio of work accomplished $\cdot \min ^{-1}\left(\mathrm{~kJ} \cdot \mathrm{min}^{-1}\right)$ to metabolic energy expended $\cdot \mathrm{min}^{-1}\left(\mathrm{~kJ} \cdot \mathrm{min}^{-1}\right)$ (Chavarren \& Calbet, 1999). Since relative intensity of the cycling bouts could be superior to ventilatory threshold (VT), the aerobic contribution to metabolic energy was calculated from the energy equivalents for oxygen (according to respiratory exchange ratio value) and a possible anaerobic contribution was estimated using blood lactate increase with time ( $\Delta$ lactate: $63 \mathrm{~J} \cdot \mathrm{kg}^{-1} \mathrm{mM}^{-1}$, di Prampero 1981). For this calculation, $\mathrm{VO}_{2}$ and lactate increase was estimated from the difference between the 10th and 3rd minutes.

All the measured variables were expressed as mean and standard deviation $(M \pm S D)$. Differences in biomechanical and physiological parameters between the three conditions (CTRL vs. SCA; CTRL vs. SCD; SCA vs. SCD trials) as well as 
differences between the values recorded during the downstroke of the dominant and the downstroke of the nondominant leg (MTD vs. MTND; PTD vs. PTND; AD vs. AND) were analyzed using a Wilcoxon test. The level of confidence was set at $p<0.05$.

\section{Results}

The test to determine leg dominance showed that among the 8 participants, 6 were left-leg dominant and only 2 were right-leg dominant. During the maximal test, the observation of a plateau in $\mathrm{VO}_{2}\left(\right.$ mean value for $\mathrm{VO}_{2} \max : 68.6 \pm 7.5 \mathrm{ml} \cdot \mathrm{min}^{-1} \cdot \mathrm{kg}^{-1}$ ) and HRmax and RERmax values (respectively, $191 \pm 8$ beats $\cdot \mathrm{min}^{-1}$ and $1.06 \pm$ 0.05 ) showed that 2 out of 3 criteria for attainment of $\mathrm{VO}_{2} \max$ were met (Howley et al., 1995). MAP values $(342 \pm 41 \mathrm{~W})$ were close to those previously obtained for triathletes of the same level (Brisswalter, Hausswirth, Smith, Vercruyssen, \& Vallier, 2000; Garside \& Doran, 2000). The cycling exercises were performed at a mean power output of $259 \pm 30 \mathrm{~W}$, which was $75 \%$ of MAP.

There was no significant difference in performance between the two swimming trials (respectively for SCD and SCA: $653 \pm 43 \mathrm{~s}$, and $654 \pm 43 \mathrm{~s}, p>0.05$ ). The mean velocity of the two $750-\mathrm{m}$ was therefore $1.15 \mathrm{~m} \cdot \mathrm{s}^{-1}$. In contrast, HR values recorded during the last $5 \mathrm{~min}$ of swimming and blood lactate concentration measured immediately after swimming were significantly lower in the SCD trial than in the SCA trial (mean HR values of $160 \pm 16$ vs. $171 \pm 18$ beats $\mathrm{min}^{-1}$, and blood lactate concentrations of $5.7 \pm 1.8 \mathrm{vs} .8 .0 \pm 2.1 \mathrm{mmol} \cdot \mathrm{L}^{-1}$, respectively, for SCD and SCA trials, $p<0.05)$. Furthermore, RPE values recorded immediately after swimming indicated that the participants' perception of effort was significantly lower in the SCD trial than in the SCA trial $(13 \pm 2$ vs. $15 \pm 1$, corresponding to "rather laborious" vs. "laborious," respectively, for SCD and SCA trials, $p<0.05$ ).

The biomechanical and physiological parameters measured during cycling in CTRL, SCD, and SCA trials are listed in Tables 1 and 2. No significant difference between SCD and CTRL trials was observed for all biomechanical parameters measured. Moreover, in spite of significantly higher blood lactate levels during cycling in the SCD compared with the CTRL trial (Table 2, $p<0.05$ ), the GE and $\mathrm{VO}_{2}$ values recorded during these two these trials were not significantly different (Table 2, $p>0.05$ ).

Table 1 shows that several biomechanical parameters recorded during cycling were significantly different in the SCA trial compared to the SCD trial. The participants adopted a significantly lower pedal rate after the swimming bout performed in a drafting position than after the swimming bout performed alone (Table $1, p<0.05$ ). Consequently, the mean resultant torque measured at the crank axle was significantly higher in SCD than in SCA (MTD and MTND, Table 1, $p<0.05$ ). A higher resultant peak torque was also observed during the SCD trial compared with the SCA trial. However, this difference was significant only during the downstroke of the nondominant leg (PTND, Table 1, $p<0.05$ ). Moreover, MTD was significantly higher when compared with MTND in all trials (CTRL, SCD, and SCA, Table 1, $p<$ 0.05 ), suggesting an asymmetry between the mean torques exerted by the dominant leg and the nondominant leg.

A significant difference was also shown between PTD and PTND during the SCA and SCD trials only (Table $1, p<0.05$ ). The results concerning physiological parameters demonstrate that swimming in a drafting position induced significantly lowered $\mathrm{VO}_{2}$ and blood lactate values during subsequent cycling compared with a 
Table 1 Mean Values of Biomechanical Parameters Recorded During Cycling in CTRL, SCD, and SCA Trials

\begin{tabular}{llll}
\hline & CTRL & SCD & SCA \\
\hline Pedal rate $\left(\mathrm{rev} \cdot \mathrm{min}^{-1}\right)$ & $85.1 \pm 8.1$ & $85.0 \pm 6.2$ & $90.2 \pm 8.8^{\mathbf{b}}$ \\
MTD $(\mathrm{Nm})$ & $31.2 \pm 3.5$ & $31.3 \pm 3.2$ & $30.2 \pm 3.5^{\mathbf{b}}$ \\
MTND $(\mathrm{Nm})$ & $30.0 \pm 3.6$ & $29.8 \pm 3.4$ & $28.6 \pm 3.5^{\mathbf{a}, \mathbf{b}, \mathbf{c}}$ \\
PTD $(\mathrm{Nm})$ & $46.2 \pm 5.2$ & $47.4 \pm 5.1$ & $46.0 \pm 6.2^{\mathbf{b}}$ \\
PTND $(\mathrm{Nm})$ & $44.6 \pm 7.7$ & $44.8 \pm 6.6$ & $43.6 \pm 6.9^{\mathbf{b}, \mathbf{c}}$ \\
AD (degrees) & $80.3 \pm 10.7$ & $83.3 \pm 6.5$ & $81.8 \pm 8.3$ \\
AND (degrees) & $79.3 \pm 13.6$ & $82.4 \pm 11.5$ & $82.7 \pm 16.7$ \\
\end{tabular}

Note $:$ MTD = mean resultant torque exerted during downstroke of dominant leg; MTND = mean resultant torque exerted during downstroke of nondominant leg; PTD = peak resultant torque exerted during downstroke of dominant leg; PTND = peak resultant torque exerted during downstroke of nondominant leg; $\mathrm{AD}=$ crank angle corresponding to PTD; $\mathrm{AND}=$ crank angle corresponding to PTND.

Significantly different, $p<.05$ : from CTRL trial; brom SCD trial; from dominant side.

Table 2 Mean Values of Physiological Parameters Recorded During Cycling in CTRL, SCD, and SCA Trials

\begin{tabular}{|c|c|c|c|c|}
\hline & & CTRL & SCD & SCA \\
\hline $\mathrm{VO}_{2}\left(\mathrm{~L} \cdot \mathrm{min}^{-1}\right)$ & & $3.90 \pm 0.50$ & $3.83 \pm 0.53$ & $4.03 \pm 0.54^{b}$ \\
\hline \multirow[t]{2}{*}{$\mathrm{LA}\left(\mathrm{mmol} \cdot \mathrm{L}^{-1}\right)$} & $3 \mathrm{~min}$ & $4.5 \pm 0.8$ & $6.6 \pm 1.9$ & $7.9 \pm 1.9^{\mathbf{a}, \mathbf{b}}$ \\
\hline & $10 \mathrm{~min}$ & $4.8 \pm 2.2$ & $6.8 \pm 2.4$ & $8.2 \pm 2.7^{\mathbf{a}, \mathbf{b}}$ \\
\hline GE $(\%)$ & & $19.1 \pm 1.5$ & $19.5 \pm 1.6$ & $18.5 \pm 0.6^{\mathbf{b}}$ \\
\hline
\end{tabular}

Note $\mathrm{VO}_{2}=$ oxygen uptake; $\mathrm{LA}=$ blood lactate concentration; $\mathrm{GE}=$ gross efficiency.

Significantly different, $p<.05$ : from CTRL trial; ${ }^{\mathbf{b}}$ from SCD trial.

prior swimming bout performed alone (Table 2, $p<0.05$ ). Therefore, cycling gross efficiency was significantly higher in the SCD trial than in the SCA trial (Table 2, $p$ $<0.05)$. Finally, the SCA trial was also characterized by a significantly lower RMT and significantly higher lactate values measured during cycling compared with the CTRL trial (Tables 1 and 2, $p<0.05$ ).

\section{Discussion}

The main results of this study indicated that the lower metabolic load when swimming in a drafting position resulted in a modification of the locomotor pattern adopted in cycling and a better efficiency of cycling after the swim-to-cycle transition. Indeed, a significantly lower pedal rate and significantly higher mean and peak resultant torques were observed in the SCD trial compared with the SCA trial. 
The observation of a decrease in movement frequency following prior swimming in a drafting position is in accordance with results previously observed during the cycle-to-run transition. Indeed, Hausswirth et al. (2001) compared the influence of two drafting strategies during the $20-\mathrm{km}$ cycling stage of a sprint triathlon on subsequent $5-\mathrm{km}$ running performance, i.e., drafting continuously behind a leader or alternating drafting and leading every $500 \mathrm{~m}$ at the same pace. They showed that the continuous drafting strategy during cycling involved a significant decrease in SR $(6.6 \%)$ during the first $\mathrm{km}$ of running when compared to the alternate drafting strategy.

More recently, Bernard, Vercruyssen, Grego, et al. (2003) observed that the lower metabolic load associated with the adoption of a pedal rate of 60 vs. 100 rev. $\min ^{-1}$ during a 20 -min cycling bout at an average power output of $276 \mathrm{~W}$ resulted in a significant decrease in SR during the first 500-m of a subsequent 3,000-m run undertaken at competition pace $(1.48 \pm 0.03 \mathrm{~Hz}$ vs. $1.51 \pm 0.05 \mathrm{~Hz}$, respectively, for the 60 and $100 \mathrm{rev} \cdot \mathrm{min}^{-1}$ conditions). The decrease in pedal rate measured in the present study (5.8\%) is comparable to these previous results. Furthermore, Hausswirth et al. (2001) reported that the lower running SR following the continuous cycling drafting strategy was accompanied by a significant improvement in running speed (4.2\%). This suggests that the decrease in pedal rate observed in the present study may lead to performance improvement during the cycling bout of the SCD trial compared with the SCA trial. Since these cycling bouts were undertaken at the same power output, a better performance in this case could be achieved through a decrease in energy expenditure.

The main hypothesis proposed in the literature to account for the modifications of SR or pedal rate during multisport activities is relative to the relationship between the movement frequencies of successive exercises. Bernard et al. (2003) suggested that the decrease in SR observed in their study at the start of the 3,000-m run in the $60 \mathrm{vs}$. the $100 \mathrm{rev} \cdot \mathrm{min}^{-1}$ condition was directly related to the lower pedal rate adopted during prior cycling. In the present study, the decrease in pedal rate observed in the SCD trial compared with the SCA trial could in part be accounted for by the locomotor pattern adopted during prior swimming. Indeed, significant decreases in arm stroke frequency have been reported when swimming in a drafting position vs. swimming alone, from $2.5 \%$ to $5.6 \%$ (Chatard, Chollet, \& Millet, 1998; Chatard \& Wilson, 2003). If the participants adopt the same leg kick pattern in the drafting and isolated conditions (i.e., 2- or 6-beat per arm stroke for triathletes), a lower absolute frequency of leg kicks could therefore be expected in the SCD trial compared with the SCA trial. This lower kick rhythm could be partly responsible for the significant decrease in pedal rate at the onset of cycling in SCD vs. SCA.

The lower pedal rate observed in the present study was associated with a significantly higher cycling gross efficiency in the SCD trial compared to the SCA trial. The energy expenditure occurring during prolonged exercises, considered one of the main determinants of successful performance (Brisswalter et al., 2000; O'Toole \& Douglas, 1995), is commonly related to the modifications in the biomechanical aspects of locomotion (Hausswirth et al., 1997). Among the biomechanical parameters often suggested to account for the increase in energy expenditure during cycling events, the pedal rate spontaneously adopted by the athletes is one of the most frequently cited in the literature (Brisswalter et al., 2000; Vercruyssen et al., 2001). Several studies have shown a curvilinear relationship between $\mathrm{VO}_{2}$ or energy cost and pedal rate during short cycling trials (maximal duration of $30 \mathrm{~min}$ ) performed 
by triathletes. This relationship allowed them to determine an energetically optimal cadence (EOC), defined as the pedal rate associated with the lower $\mathrm{VO}_{2}$ or energy cost value, ranging from 72.5 to $86 \mathrm{rev} \cdot \mathrm{min}^{-1}$ among the studies (Brisswalter et al., 2000; Vercruyssen et al., 2001; 2002).

Interestingly, the value of EOC seems to depend on cycling intensity. Indeed, a linear increase in EOC has been reported in trained cyclists when power output was raised from 100 to $300 \mathrm{~W}$ (Coast \& Welch, 1985). In the present study, the pedal rate adopted by the triathletes in the SDC trial $\left(85 \mathrm{rev} \cdot \mathrm{min}^{-1}\right)$ was in the range of the EOC identified in previous studies. This could help explain the lower energy expenditure observed in this trial compared with the SCA trial. When the pedal rate is increased from the EOC, as is the case in the SCA trial, a higher metabolic load is classically reported. This elevation in energy expenditure could be related either to an increase in internal work occurring during repetitive limb movements (Francescato, Girardis, \& di Prampero, 1995), or to a higher cost of ventilation (Coast, Rasmussen, Krause, et al., 1993).

The adoption of a particular pedal rate by cyclists or triathletes during competition could be related to several criteria. The parameters most often cited in the literature are a minimization of neuromuscular fatigue, a decrease in the force applied on the cranks, and a reduction of stress in the muscles of the lower limbs (Neptune \& Hull, 1999; Patterson \& Moreno 1990; Takaishi, Yasuda, Ono, \& Moritani, 1996). Within this framework, pedaling at a higher rate is theoretically associated with a lowering of the pedaling force produced by the muscles of the lower limbs to maintain a given power output, delaying the onset of local neuromuscular fatigue (Takaishi et al., 1996).

This relationship has been reported in several studies, showing that the peak forces applied on the pedals were significantly lower with the elevation of pedal rate at constant power output (Patterson \& Moreno, 1990; Sanderson, 1991). But Patterson and Moreno (1990) also showed that the average resultant pedal force produced during short cycling trials varied with the pedal rate adopted by the participants, reaching minimum values at $90 \mathrm{rev} \cdot \mathrm{min}^{-1}$ when power output was 100 $\mathrm{W}$ and $100 \mathrm{rev} \cdot \mathrm{min}^{-1}$ for a higher power output $(200 \mathrm{~W})$. Moreover, Neptune and Hull (1999) have reported that during a 5-min ride at $265 \mathrm{~W}$, the minimum values of 9 indices representative of muscle activation, force, stress, and endurance for 14 muscles of the lower limbs were obtained when the participants adopted a pedal rate of $90 \mathrm{vs} .75$ and $105 \mathrm{rev} \cdot \mathrm{min}^{-1}$. They referred to this cadence $\left(90 \mathrm{rev} \cdot \mathrm{min}^{-1}\right)$ as the theoretical mechanical optimal cadence. In the SCA trial of the present study, the pedal rate adopted by the triathletes $\left(91.1 \mathrm{rev} \cdot \mathrm{min}^{-1}\right)$ corresponds to the mechanical optimal cadence.

It could therefore be suggested that following the high intensity swim, involving a possible decrease in leg muscular capacity, the triathletes were more fatigued and intrinsically adopted a pedal rate close to mechanical optimal cadence in order to minimize neuromuscular fatigue. Conversely, following the swim at a lower relative intensity (SDC trial), they were less fatigued and therefore spontaneously chose a lower pedal rate associated with higher torques. However, this hypothesis must be considered with caution because the decreases in resultant torques observed with increasing cadence in the present study are smaller than the decreases in peak forces reported in previous studies for comparable power outputs (4.2\% for this study vs. $13 \%$ for Patterson \& Moreno, 1990).

The variation of the torques exerted during cycling in the 3 trials of this 
study shows an asymmetry between the dominant leg and the nondominant leg. Indeed, the MTD were significantly higher compared to the MTND in all trials and the PTD were significantly higher than the PTND in the SCD and SCA trials. The observation of significantly higher torques or forces exerted by the dominant leg compared to the other leg during cycling has been classically reported in the literature (Daly \& Cavanagh, 1976; Sargeant \& Davies, 1977). This asymmetry seems to become more important with fatigue. Within this framework, McCartney, Heigenhauser, Sargeant, and Jones (1983) found that the difference in maximal peak torque production between legs during a short-term all-out ride increased with the duration of exercise, reaching more than $15 \%$ for some participants at the end of exercise.

The results of the present study are in accordance with these findings. Indeed, the differences in torque between the dominant and nondominant legs were more important in the trials preceded by a swimming bout compared with the CTRL trial (5.0\% and 5.6\% vs. $4.0 \%$, respectively, in SCD, SCA, and CTRL for mean torques; $5.8 \%$ and $5.5 \%$ vs. $3.6 \%$, respectively, in SCD, SCA, and CTRL for peak torques). In addition, the difference between PTD and PTND in the CTRL trial was not statistically significant. Finally, although the PTND was significantly higher in the SCD trial compared to the SCA trial, no significant difference between these trials was observed for PTD. This suggests that the dominant leg might be less sensitive to fatigue and/or cadence manipulation compared to the weakest leg. In the context of the swim-to-cycle trial of a sprint triathlon, asymmetry might only have a small influence on performance for two main reasons. First, the resultant torques vary to a small extent between the dominant and nondominant legs. Second, the duration of the cycling leg of sprint triathlons is usually quite short (approx. 29 min $22 \mathrm{sec}$ in the study by Hausswirth et al., 2001), and therefore fatigue is less likely to occur than in long-distance events.

In conclusion, this study shows that the conditions of a 750-m swimming bout could affect biomechanical adaptation during subsequent cycling. In particular, when prior swimming was performed in a drafting position, the triathletes adopted a significantly lower pedal rate associated with higher mean and peak resultant torques recorded at the crank axle. These modifications could be partly explained by the delayed appearance of fatigue in the cycling bout of the SCD trial compared with the SCA trial. Needed are further studies that include measurements of the force applied on the pedals so we can more precisely examine the influence of prior swimming on the biomechanics of force application during cycling at a constant power output.

\section{Acknowledgments}

The authors are grateful to all the triathletes who took part in the experiment and acknowledge their wholehearted cooperation and motivation.

\section{References}

Bernard, T., Vercruyssen, F., Grego, F., Hausswirth, C., Lepers, R., Vallier, J.M., \& Brisswalter, J. (2003). Effect of cycling cadence on subsequent $3 \mathrm{~km}$ running performance in well trained triathletes. British Journal of Sports Medicine 37, 154-158. 
Borg, G.A.V. (1970). Perceived exertion as an indicator of somatic stress. Scandinavian Journal of Rehabilitation and Medicine 2, 92-98.

Brisswalter, J., Fougeron, B., \& Legros, P. (1998). Variability in energy cost and walking gait during race walking in competitive race walkers. Medicine and Science in Sports and Exercise 30, 1451-1455.

Brisswalter, J., Hausswirth, C., Smith, D., Vercruyssen, F., \& Vallier, J.M. (2000). Energetically optimal cadence vs. freely-chosen cadence during cycling: Effect of exercise duration. International Journal of Sports Medicine 20, 60-64.

Cavanagh, P.R., \& Williams, K.R. (1982). The effect of stride length variation on oxygen uptake during distance running. Medicine and Science in Sports and Exercise 14 30-35.

Chatard, J.C., Chollet, D., \& Millet, G.P. (1998). Performance and drag during drafting swimming in highly trained triathletes. Medicine and Science in Sports and Exercise 30, 1276-1280.

Chatard, J.C., \& Wilson, B. (2003). Drafting distance in swimming. Medicine and Science in Sports and Exercise 35, 1176-1181.

Chavarren, J., \& Calbet, J.A. (1999). Cycling efficiency and pedalling frequency in road cyclists. European Journal of Applied Physiology 80, 555-563.

Coast, J.R., Rasmussen, S.A., Krause, K.M., O’Kroy, J.A., Loy, R.A., \& Rhodes, J (1993). Ventilatory work and oxygen consumption during exercise and hyperventilation. Journal of Applied Physiology 74, 793-798.

Coast, J.R., \& Welch, H.G. (1985). Linear increase in optimal pedal rate with increased power output in cycle ergometry. European Journal of Applied Physiology and Occupational Physiology 53, 339-342.

Daly, D.J., \& Cavanagh, P.R (1976). Asymmetry in bicycle ergometer pedaling. Medicine and Science in Sports 8, 204-208.

Dengel, D.R., Flynn, M.G., Costill, D.L., \& Kirwan, J.P (1989). Determinants of success during triathlon competition. Research Quarterly 60, 234-238.

di Prampero, P.E. (1981). Energetics of muscular exercise. Review of Physiology, Biochemistry and Pharmacology 89, 144-222.

Elliot, B.C., \& Roberts, A.D. (1980). A biomechanical evaluation of the role of fatigue in middle distance running. Canadian Journal of Applied Sport Science 5, 203-207.

Francescato, M.P., Girardis, M., \& di Prampero, P.E. (1995). Oxygen cost of internal work during cycling. European Journal of Applied Physiology 72, 51-57.

Garside, I., \& Doran, D.A. (2000). Effects of bicycle frame ergonomics on triathlon 10-km running performance. Journal of Sports Sciences 18, 825-833.

Hausswirth, C., Bigard, A.X., \& Guezennec, C.Y. (1997). Relationships between running mechanics and energy cost of running at the end of a triathlon and a marathon. International Journal of Sports Medicine 18, 330-339.

Hausswirth, C., Lehenaff, D., Dreano, P., \& Savonen, K. (1999). Effects of cycling alone or in a sheltered position on subsequent running performance during a triathlon. Medicine and Science in Sports and Exercise 31, 599-604.

Hausswirth, C., Vallier, J., Lehenaff, D., Brisswalter, J., Smith, D., Millet, G., \& Dreano, P (2001). Effect of two drafting modalities in cycling on running performance. Medicine and Science in Sports and Exercise 33, 1-8.

Howley, E.T., Bassett, D.R., \& Welch, H.G. (1995). Criteria for maximal oxygen uptake: Review and commentary. Medicine and Science in Sports and Exercise 27, 12921301. 
Jones, S.M., \& Passfield, L. (1998). The dynamic calibration of bicycle power measuring cranks. In S.J. Haake (Ed.), The engineering of sport (pp. 265-274). Oxford: Blackwell Scientific.

Lepers, R., Hausswirth, C., Maffiuletti, N.A., Brisswalter, J., \& Van Hoecke, J. (2000). Evidence of neuromuscular fatigue after prolonged cycling exercise. Medicine and Science in Sports and Exercise 32, 1880-1886.

McCartney, N., Heigenhauser, G.J., Sargeant, A.J., \& Jones, N.L. (1983). A constant-velocity cycle ergometer for the study of dynamic muscle function. Journal of Applied Physiology 55, 212-217.

McLaughlin, J.E., King, G.A., Howley, E.T., Basset, D.R., \& Ainsworth, B. (2001). Validation of the Cosmed $\mathrm{K} 4 \mathrm{~b}^{2}$ portable metabolic system. International Journal of Sports Medicine 22, 280-284.

Millet, G.P., Millet, G.Y., \& Candau, R.B. (2001). Duration and seriousness of running mechanics alterations after maximal cycling in triathletes. Journal of Sports Medicine and Physical Fitness 41, 147-153.

Neptune, R.R., \& Hull, M.L. (1999). A theoretical analysis of preferred pedaling rate selection in endurance cycling. Journal of Biomechanics 32, 409-415.

O'Toole, M.L., \& Douglas, P.S. (1995). Applied physiology of a triathlon. Sports Medicine 19, 251-267.

Patterson, R.P., \& Moreno, M.I (1990). Bicycle pedalling forces as a function of pedalling rate and power output. Medicine and Science in Sports and Exercise 22, 512-516.

Quigley, E.J., \& Richards, J.G. (1996). The effects of cycling on running mechanics. Journal of Applied Biomechanics 12, 470-479.

Sanderson, D.J (1991). The influence of cadence and power output on the biomechanics of force application during steady-rate cycling in competitive and recreational cyclists. Journal of Sports Sciences 9, 191-203.

Sargeant, A.J., \& Davies, C.T. (1977). Forces applied to cranks of a bicycle ergometer during one- and two-leg cycling. Journal of Applied Physiology 42, 514-518.

Schabort, E.J., Killian, S.C., St Clair Gibson, A., Hawley, J.A., \& Noakes, T.D. (2000). Prediction of triathlon race time from laboratory testing in national triathletes. Medicine and Science in Sports and Exercise 32, 844-849.

Takaishi, T., Yasuda, Y., Ono, T., \& Moritani, T. (1996). Optimal pedaling rate estimated from neuromuscular fatigue for cyclists. Medicine and Science in Sports and Exercise 28, 1492-1497.

Vercruyssen, F., Hausswirth, C., Smith, D., \& Brisswalter, J. (2001). Effect of exercise duration on optimal pedaling rate choice in triathletes. Canadian Journal of Applied Physiology 26, 44-54.

Vercruyssen, F., Brisswalter, J., Hausswirth, C., Bernard, T., Bernard, O., \& Vallier, J.M. (2002). Influence of cycling cadence on subsequent running performance in triathletes. Medicine and Science in Sports and Exercise 34, 530-536. 